\title{
Load Carrying Capacity of Adiabatically Lubricated Thrust Bearings with Various Film Profiles
}

\author{
N. Anandan*, P. Sathiamurugan, P. Mathiazhagan \\ Department of Mechanical Engineering, Pondicherry Engineering College, Puducherry,-605014, India \\ *Corresponding Author: anandhane@gmail.com
}

Copyright (C) 2014 Horizon Research Publishing All rights reserved.

\begin{abstract}
The effect of various film profiles on the load carrying capacity of adiabatically lubricated fixed pad thrust bearing is analyzed in this work. One dimensional film thickness profiles such as taper, polynomial, catenoidal, exponential and truncated cycloidal are employed here to predict the load carrying capacity of the fixed pad thrust bearings. Results are computed for various levels of speeds $(5 \mathrm{~m} / \mathrm{s}, 15 \mathrm{~m} / \mathrm{s}, 25 \mathrm{~m} / \mathrm{s})$ at two levels of viscosity $(0.5 \mathrm{Pas}$, $0.05 \mathrm{Pas})$. The shape of the film profile do influence the load carrying capacity of the thrust bearings and the polynomial film thickness profile has the maximum influence when compared to other film profiles.
\end{abstract}

Keywords Thrust Bearings, Hydrodynamic Lubrication, Film Thickness Profiles, Adiabatic, Load Carrying Capacity

\section{Introduction}

Hydro dynamically lubricated thrust bearings have been widely used to support high-speed rotating machinery such as generators, turbines, compressors, pump, engine cranks, gear boxes, large milling systems etc. In common with other types of hydrodynamic bearings, the fixed pad bearing also depends for its operation, the need for lubricant being drawn into the wedge-shaped spaces, thus producing pressure which counteracts the load and prevents contact between the sliding parts. Any pad profile which gives convergence in the direction of motion to the lubricant film may be used. Since the film shape being considered here is continuously convergent from inlet to outlet, there is no cause for the formation of negative pressure similar to those which occur in journal bearings. As the rotational speed of the bearing increases, the temperature of the lubricant will rise considerably, and the constant viscosity assumption is not true since the viscosity of the liquid always decreases as the temperature increases.

Lubrication of the sliding components reduces the frictional resistance between the moving surfaces which in turn leads to reduced wear. The energy consumed by these bearings while overcoming friction appears as heat which causes a rise in the temperature of oil. High temperature rise if not dissipated properly causes reduction in the fatigue life of the bearing materials, decrease in the viscosity of the lubricant which in turn reduces the load carrying capacity and increases the frictional power loss. In order to correctly predict the load carrying capacity of the bearings, designers have to take into account not only the pressure effects but also the thermal effects. If all the heat generated in the contact will be dissipated in the oil itself rather than being conducted into the bearing surfaces then it is termed as adiabatic analysis. Total pressure generated in any bearing depends on the total area of computational domain which in turn depends not only on the inlet and outlet film thicknesses but also on the profile of the film thickness between the inlet and the outlet.

Thrust bearings have been studied for many years. Zakharov [1] reviewed the progress in the theory and calculation involved in the modeling of hydrodynamic lubrication. Various authors studied the thrust bearings [2-4] over the years. Robinson and Cameron [3] used interferometry to study thrust bearings. Huebner [4] presented a finite element formulation for the equations governing the steady thermo hydrodynamic behaviour of thrust bearings. Various researchers studied the thermal effects in the bearing through the adiabatic route [5-8]. Jang and Chang [6] presented adiabatic solutions for a finite width hydrodynamic journal bearing with non-Newtonian lubricants. Jang et al. [8] gave adiabatic solutions for a finite width, hydrodynamic journal bearing with rough surfaces. Authors also found that the effect of roughness direction on the maximum temperature is not significant when compared with its effect on the load carrying capacity. Singh [9] and Bagci and Singh [10] investigated hydrodynamically lubricated slider bearing having different film shapes and studied the effect of film shapes on the performance of thrust bearings. Authors listed the results based on the film thickness ratio and dimensions of the pad while excluding the thermal effects. Sharma and Pandey [11] presented the effect of cycloidal profiled pad thrust bearing over the plane profiled thrust bearing and found that the load carrying capacity of cycloidal profiled thrust bearing is greater than 
that of plane profiled thrust bearing. Authors did not consider the influence of other film profiles on the thrust bearing. Sharma and Pandey [12] compared the experimental results of pressure distributions in slider bearing with various single continuous surface profiles of pads while using both clean and contaminated lubricating oils.

Andharia et al. [13] studied the effect of surface roughness on the performance of the hydro dynamically lubricated thrust bearings with various film profiles. Shah and Bhat [14] analysed the lubrication by ferro fluids in a porous secant shaped slider bearings. From the literature cited here, it can be inferred that there is no work which takes into account thermal effects adiabatically on the load carrying capacity for various film thickness profiles. Hence, this present work attempts to predict the load carrying capacity of thrust bearings while including the thermal effects adiabatically with various film shapes.

\section{Mathematical Modelling}

The bearing configuration consists of two surfaces separated by a lubricant film. The $\mathrm{X}$ axis is taken along the lower plane across its length, while the $\mathrm{Z}$ axis is taken across the lubricant film. The lower surface is moving with a velocity $\mathrm{U}$ in the $\mathrm{X}$ direction while the upper surface is stationary. Both the surfaces are considered to be infinitely wide in the $\mathrm{Y}$ direction. An accurate analysis of the hydrodynamics of fluid film can be obtained from the coupled solution of Reynolds and the energy equations.

2.1. Reynolds equation. The generalized Reynolds equation can be deduced from Navier-Stokes equations and continuity equations under certain assumptions. Such as the lubricant is Newtonian, inertia and gravitational effect on the lubricant film are neglected. The film thickness is small compared with the radius of curvature of the bearing surfaces. Steady state conditions apply. The one dimensional Reynolds equation is presented in (1).

$$
\frac{\partial}{\partial x}\left[h^{3} \frac{\partial p}{\partial x}\right]=6 u \eta\left[\frac{\partial h}{\partial x}\right]
$$

2.2. Energy equation. The energy equation (2) is a simplified form of the heat transfer equation commonly used. The terms present in the heat transfer equation can be eliminated by an order of magnitude analysis to yield only convection terms. The temperature of runner has been assumed constant and set equal to inlet oil temperature.

$$
\frac{\partial}{\partial x}\left[\rho u{ }_{p} T\right]+\frac{\partial}{\partial z}\left[\rho w c_{p} T\right]-k \frac{\partial^{2} T}{\partial z^{2}}=\eta\left[\frac{\partial u}{\partial z}\right]^{2}
$$

2.3. Boundary Conditions. For an adiabatic bearing, the temperature gradient of the lubricant becomes zero close to the static surface. The lack of temperature gradient close to the pad surface is caused by the absence of heat conduction from the lubricant to the pad. The adiabatic boundary condition can result in much higher temperatures than the isothermal one. The temperature of the rotating surface remains constant at the bearing outlet, the temperature gradient in the sliding direction declines to zero as the lubricant leaves the domain with an unchanged temperature.

The bearing inlet has a variable boundary condition which depends on the direction of lubricant film at the bearing inlet. As there is a possibility of reverse film at the inlet, in order to accommodate this, it is necessary to iterate at the inlet boundary and create an additional array of temperature nodes with values based on linear extrapolation from inside the bearing.

Boundary conditions at the pad surface changes to an unknown pad temperature but with a zero temperature gradient normal to the plane of lubricant film. In this case, it is necessary to involve an imaginary array of temperature nodes above the pad surface with values of temperature maintained equal to the adjacent pad surface temperature. Iteration then includes temperature nodes at the interface between the pad and the hydrodynamic film.

2.4. Load carrying capacity. By integrating the Reynolds equation over a specific film shape, pressure value is obtained. When the pressure is integrated over the bearing area, the corresponding load carrying capacity of the lubricating film is found. The load carrying capacity of thrust bearing can be obtained by using equation (3).

$$
W=\int_{0}^{L} P d A
$$

2.5. Frictional Force. For frictional force, assuming that the frictional force results only from shearing of the fluid and integrating the shear stress over the whole bearing area yields the total frictional force operating across the hydrodynamic film. The frictional force of the thrust bearing is presented in equation (4).

$$
F=\int_{0}^{L} \eta\left[\frac{\partial u}{\partial z}\right] d x
$$

2.6. Computational Procedure. Pad bearing problems are usually solved by finite difference methods (FDM). The Reynolds (1) and energy equations (2) are converted into FDM format. These equations are then solved by using Gauss-Seidel method till the solution converges for pressure and temperature.

2.7. Convergence criteria. The solutions of the governing equations are assumed as converged if the criteria are satisfied simultaneously for pressure and temperature as given in equations (5) and (6).

For pressure

$$
\frac{\sum\left|\left(P_{i}\right)_{n}-\left(P_{i}\right)_{n-1}\right|}{\sum\left|\left(P_{i}\right)_{n}\right|}<0.001
$$

For temperature 


$$
\frac{\sum\left|\left(T_{i}\right)_{n}-\left(T_{i}\right)_{n-1}\right|}{\sum\left|\left(T_{i}\right)_{n}\right|}<0.001
$$

2.8. Film shape equations implemented. The thrust bearing is analyzed using the five film shapes (taper flat, polynomial, catenoidal, exponential and truncated cycloidal film profiles). All the shapes [1] are defined by the mathematical equations (7) to (11).

Taper flat faced film shape

$$
h=h_{\min }\left[1+(\alpha-1) \frac{x}{L}\right]
$$

Polynomial film shape

$$
h=h_{\min }\left[1+(\alpha-1)\left(\frac{x}{L}\right)^{N}\right]
$$

Catenoidal film shape

$$
h=h_{\min }[\cosh m x] m=\frac{1}{L} \cosh ^{-1} \alpha
$$

Exponential film shape

$$
h=h_{\min }\left[e^{m x}\right] m=\frac{1}{L} \ln \alpha
$$

Truncated cycloidal film shape

$$
h=h_{\min }\left[1+2(\alpha-1)\left(\frac{x}{2 L}-\frac{1}{2 \pi} \sin \frac{2 \pi x}{2 L}\right)\right]
$$

The thrust bearing is analyzed by using five types of film shapes (taper flat, polynomial, catenoidal, exponential and truncated cycloidal) as shown in Figure 1. The input parameters are shown in Table 1.

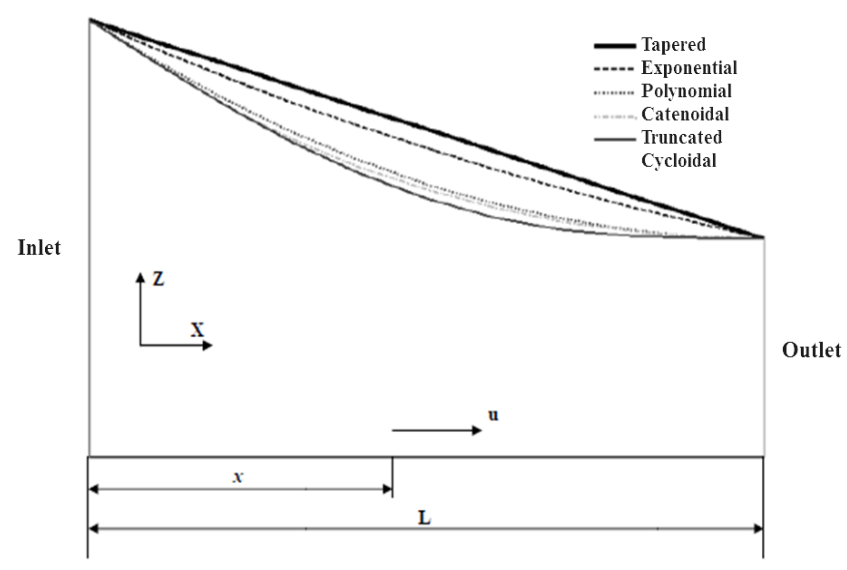

Figure 1. Comparison of film profiles

It is seen in Fig. 2 that the pressure distribution for the polynomial film profile is high when compared to the other film profiles for the sliding velocity of $5 \mathrm{~m} / \mathrm{s}$ at $0.5 \mathrm{Pas}$. When compared to taper flat faced profile, the other film profiles such polynomial, catenoidal, truncated cycloidal have higher load carrying capacity.
Table 1 Input Parameters

\begin{tabular}{cc}
\hline Parameters & Input values \\
Max. film thickness $\left(h_{\max }\right)$ & $0.1 \mathrm{~mm}$ \\
Min. film thickness $\left(h_{\min }\right)$ & $0.05 \mathrm{~mm}$ \\
Pad width $(L)$ & $0.1 \mathrm{~m}$ \\
Dynamic viscosity of lubricant $(\eta)$ & $0.5 \mathrm{Pas}$ \\
Exponential coefficient of viscosity $(\gamma)$ & $0.05 \mathrm{~K}^{-1}$ \\
Specific heat capacity of lubricant $\left(C_{p}\right)$ & $2000 \mathrm{~J} / \mathrm{kgK}$ \\
Density of lubricant $(\rho)$ & $900 \mathrm{Kg} / \mathrm{m}^{3}$ \\
Bearing inlet temperature $\left(T_{0}\right)$ & $50^{\circ} \mathrm{C}$ \\
Thermal conductivity of lubricant $(K)$ & $0.15 \mathrm{~W} / \mathrm{mK}$ \\
\hline
\end{tabular}

\section{Results and Discussion}

The results are computed at two different viscosities namely $0.5 \mathrm{Pas}$ and $0.05 \mathrm{Pas}$ for different sliding velocity values.

\subsection{Pressure Distribution}

The comparison of pressure distribution over the bearing length of all the film profiles (taper flat, polynomial, catenoidal, exponential and truncated cycloidal film profiles) are plotted in Figs. 2 to 7 for various levels of sliding velocity at two different viscosity values. From the inlet, the pressure gradually increases and towards the outlet it reaches the maximum level and then pressure decreases towards the outlet. This trend has been observed for all the profiles.

As observed in Fig. 3, for the sliding velocity of $15 \mathrm{~m} / \mathrm{s}$ at 0.5 Pas, taper flat faced film profile has lower pressure value when compared to the polynomial, catenoidal and exponential film profiles. It is seen in Fig. 4 that for the sliding velocity of $25 \mathrm{~m} / \mathrm{s}$ at $0.5 \mathrm{Pas}$, taper film profile has lower pressure value when compared to the polynomial, catenoidal and exponential film profiles.

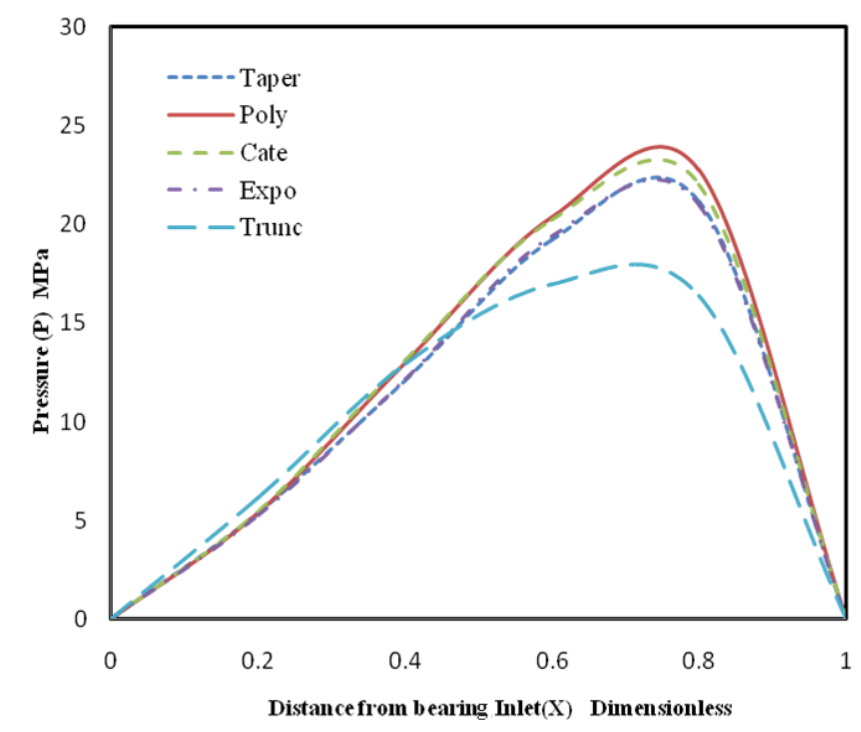

Figure 2. Comparison of pressure distribution when viscosity $=0.5 \mathrm{Pas} \&$ velocity $=5 \mathrm{~m} / \mathrm{s}$ 


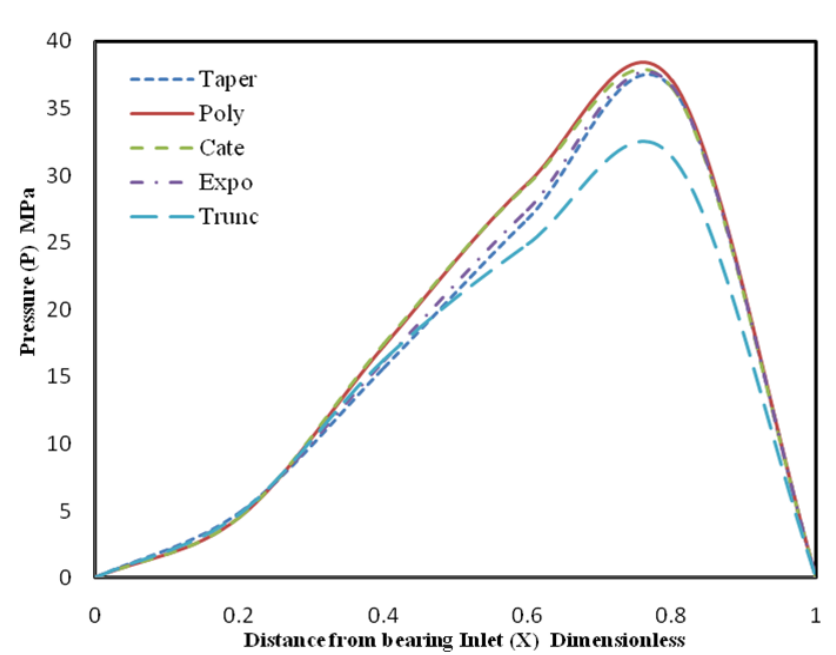

Figure 3. Comparison of pressure distribution when viscosity $=0.5 \mathrm{Pas} \&$ velocity $=15 \mathrm{~m} / \mathrm{s}$

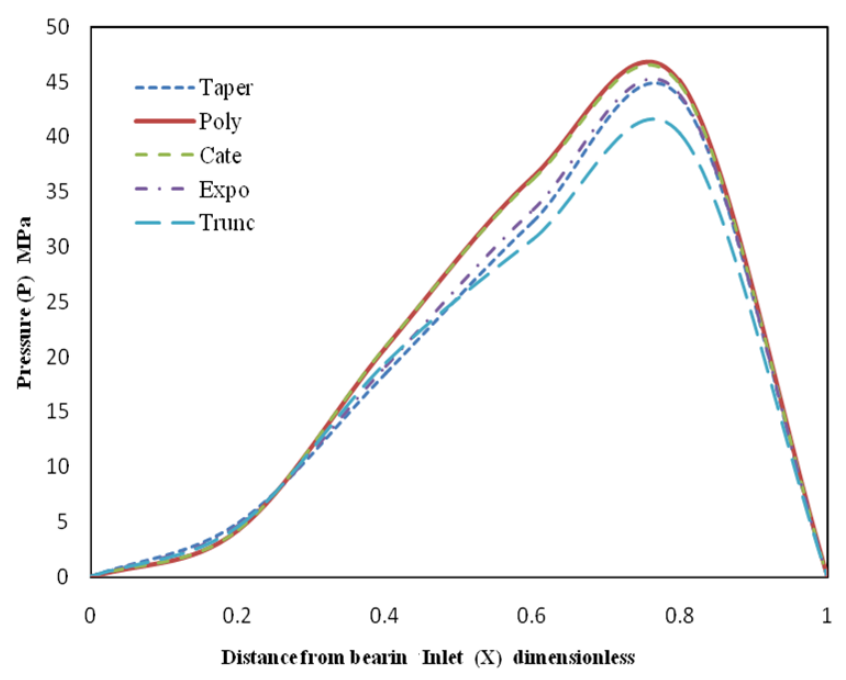

Figure 4. Comparison of pressure distribution when viscosity $=0.5 \mathrm{Pas} \&$ velocity $=25 \mathrm{~m} / \mathrm{s}$

In Fig. 5, for sliding velocity of $5 \mathrm{~m} / \mathrm{s}$ at 0.05 Pas, the polynomial film profile has considerable maximum pressure value when compared to all other film profiles.

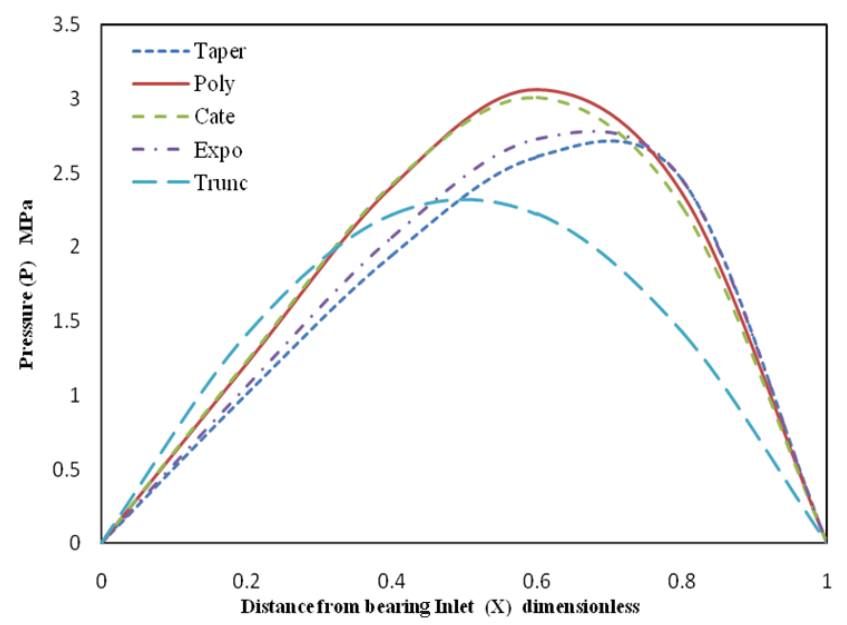

Figure 5. Comparison of pressure distribution when viscosity $=0.05$ Pas \& velocity $=5 \mathrm{~m} / \mathrm{s}$

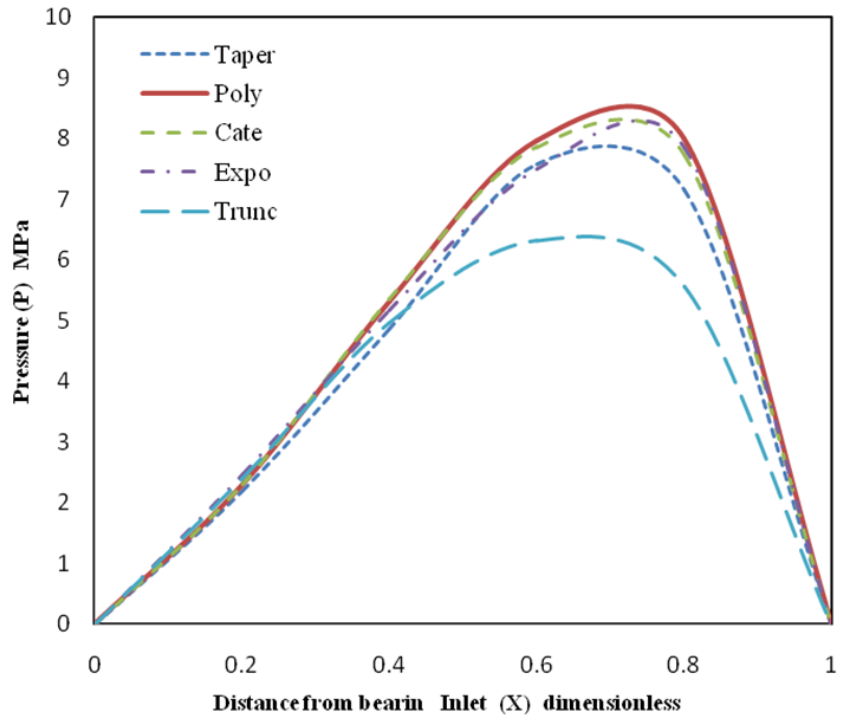

Figure 6. Comparison of pressure distribution when viscosity $=0.05 \mathrm{Pas} \&$ velocity $=15 \mathrm{~m} / \mathrm{s}$

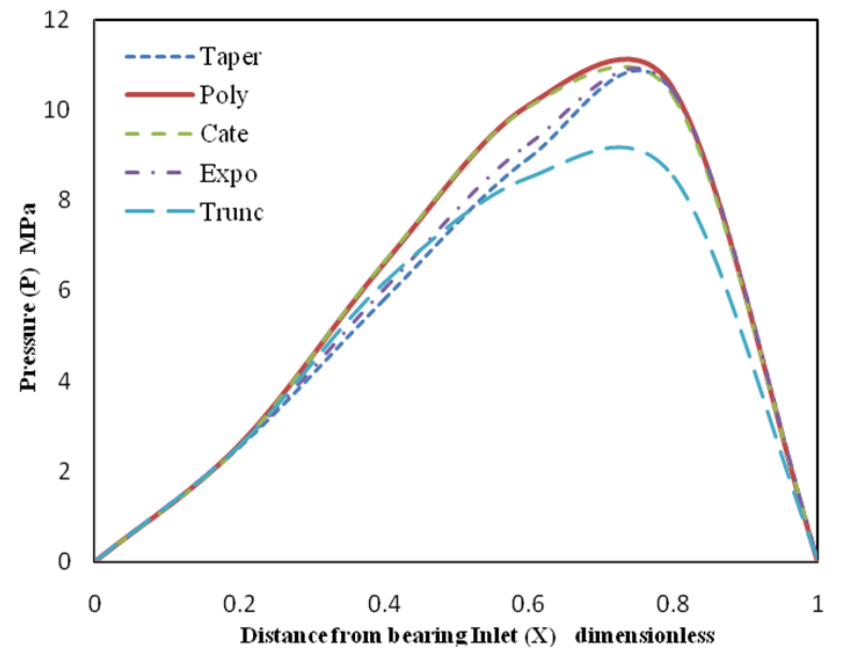

Figure 7. Comparison of pressure distribution when viscosity $=0.05 \mathrm{Pas} \&$ velocity $=25 \mathrm{~m} / \mathrm{s}$

The same increase in pressure is seen in from Figs. 6 and 7 for the polynomial film profile. It is observed that the both polynomial and catenoidal film profiles have greater magnitude of pressure than that of taper film profile. The polynomial film profile has maximum pressure than any other film profiles in Figs. 2 to 7. From all the Figs. 2 to 7, it is clearly inferred that the pressure can be improved by film shapes. It is inferred that the pressure generated depends on the geometry of the film profiles.

\subsection{Temperature Distribution}

Figs. 8 to 11 illustrate temperature distribution in the lubricated domain for various values of sliding velocity and lubricant viscosity. The temperature distributions for all the film profiles (taper flat, polynomial, catenoidal, exponential and truncated cycloidal film profiles) are drawn. It is clear that the temperature affects the performance of the bearings.

At velocity $=5 \mathrm{~m} / \mathrm{s}$, and viscosity $=0.5$ Pas, the maximum 
film temperature for taper flat face, polynomial, catenoidal, exponential and truncated cycloidal film profiles are $105.98^{\circ} \mathrm{C}, \quad 104.58^{\circ} \mathrm{C}, \quad 103.43^{\circ} \mathrm{C}, \quad 106.35^{\circ} \mathrm{C}, \quad 94.07^{\circ} \mathrm{C}$ respectively. The difference in temperature between taper and polynomial film profiles is $1.4^{\circ} \mathrm{C}$ only as shown in Figure 8 . Similarly for the velocity of $15 \mathrm{~m} / \mathrm{s}$ at $0.5 \mathrm{Pas}$, the maximum temperature for taper flat, polynomial, catenoidal, exponential and truncated cycloidal film profiles are $147.66^{\circ} \mathrm{C}, 146.10^{\circ} \mathrm{C}, 145.35^{\circ} \mathrm{C}, 146.98^{\circ} \mathrm{C}$ and $138.02^{\circ} \mathrm{C}$ respectively and are plotted in Fig. 9. The difference in temperature between taper and polynomial film profiles is $1.56^{\circ} \mathrm{C}$ only. Similarly at velocity $=25 \mathrm{~m} / \mathrm{s}$ and lubricant viscosity $=0.5 \mathrm{Pas}$, the maximum film temperature for taper flat, polynomial, catenoidal, exponential and truncated cycloidal film profiles are $165.29^{\circ} \mathrm{C}, 164.58^{\circ} \mathrm{C}, 163.97^{\circ} \mathrm{C}$, $164.87^{\circ} \mathrm{C}, 157.73^{\circ} \mathrm{C}$ respectively as shown in Fig. 10 . The same trend is also seen in Fig. 11. The difference in temperature between taper and polynomial film profile is $0.71^{\circ} \mathrm{C}$ only. It is clearly seen that the temperature increases with increase in sliding velocity.

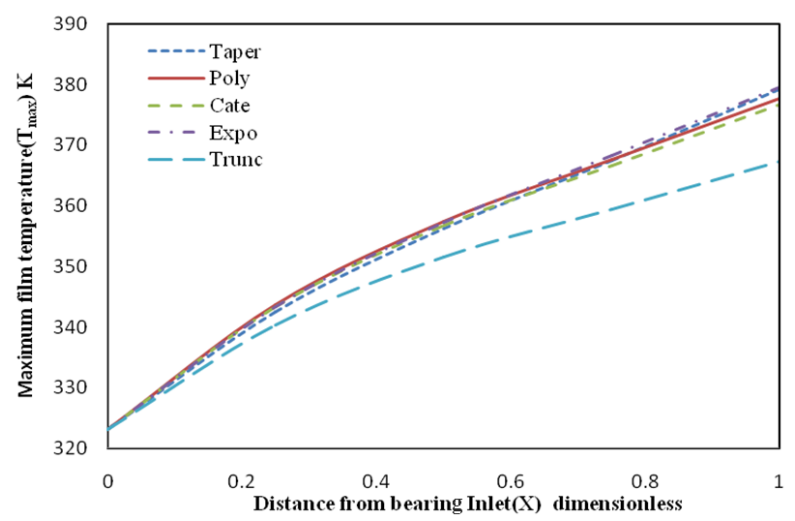

Figure 8. Temperature distribution for all film shapes when viscosity $=0.5$ Pas \& velocity $=5 \mathrm{~m} / \mathrm{s}$

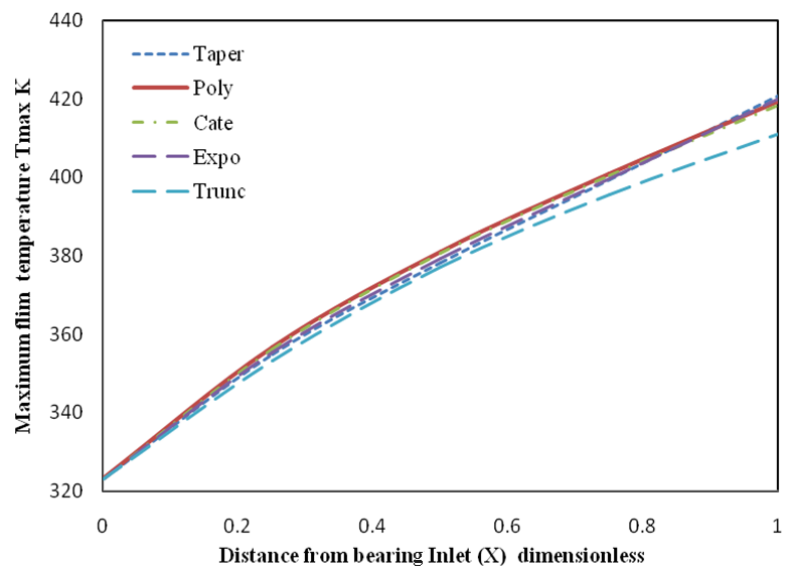

Figure 9. Temperature distribution for all film shapes when viscosity $=0.5$ Pas \& velocity $=15 \mathrm{~m} / \mathrm{s}$

\subsection{Load Carrying Capacity}

Figures 12 and 13 indicate the load carrying capacity of all the film profiles at lubricant viscosity of $0.5 \mathrm{Pas}$ and $0.05 \mathrm{Pas}$ respectively. It is clear that when the sliding velocity of the bearing increases, the load carrying capacity also increases.

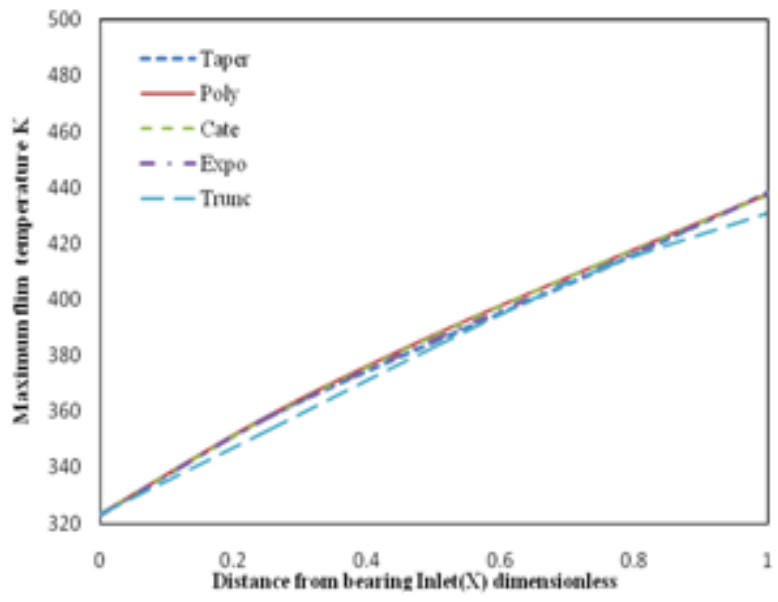

Figure 10. Temperature distribution for all film shapes when viscosity $=0.5$ Pas \& velocity $=25 \mathrm{~m} / \mathrm{s}$

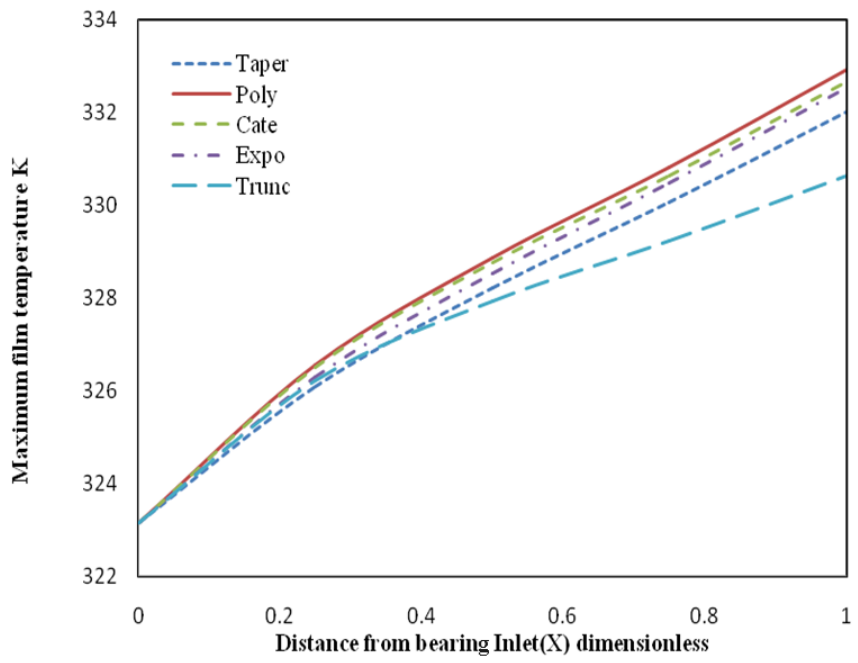

Figure 11. Temperature distribution for all film shapes when viscosity $=0.05$ Pas \& velocity $=5 \mathrm{~m} / \mathrm{s}$

When the lubricant viscosity is 0.5 Pas and sliding velocity is $5 \mathrm{~m} / \mathrm{s}$, the load carrying capacity of the taper flat, polynomial, catenoidal, exponential and truncated cycloidal film profiles are $1218800 \mathrm{~N} / \mathrm{m}, 1231000 \mathrm{~N} / \mathrm{m}, 1217200 \mathrm{~N} / \mathrm{m}$, $1215700 \mathrm{~N} / \mathrm{m}, 1049500 \mathrm{~N} / \mathrm{m}$ respectively. The difference in load carrying capacity between the polynomial and taper flat faced profiles is $12200 \mathrm{~N} / \mathrm{m}$. This increase in load carrying capacity is attributed to the film shape. The polynomial film shape has significant increase in the load carrying capacity when compared to the taper flat faced profile and other film profiles as shown in Fig. 12.

When the lubricant viscosity is 0.5 Pas and sliding velocity is $15 \mathrm{~m} / \mathrm{s}$, the load carrying capacity of the taper flat, polynomial, catenoidal, exponential and truncated cycloidal film profiles are $1678300 \mathrm{~N} / \mathrm{m}, 1766900 \mathrm{~N} / \mathrm{m}, 1756800 \mathrm{~N} / \mathrm{m}$, $1701600 \mathrm{~N} / \mathrm{m}, 1546000 \mathrm{~N} / \mathrm{m}$ respectively. The difference in load carrying capacity between the polynomial and taper flat faced profiles is $88600 \mathrm{~N} / \mathrm{m}$. This increase in load carrying 
capacity is attributed to the film shape. The polynomial film shape has significant increase in the load carrying capacity when compared to the taper flat faced profile and other film profiles.

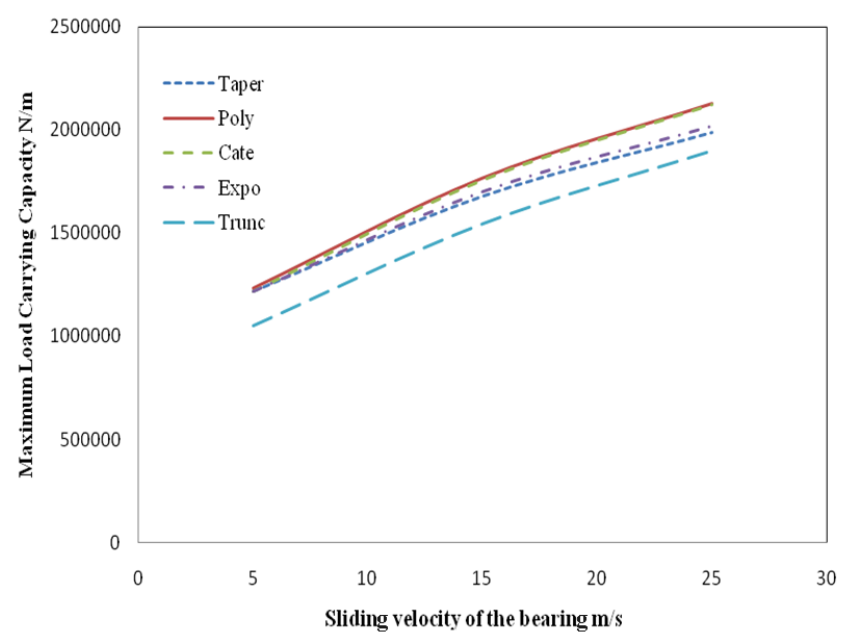

Figure 12. Comparison of Load carrying capacity for all film shapes when viscosity $=0.5$ Pas

When the lubricant viscosity is 0.5 Pas and sliding velocity is $25 \mathrm{~m} / \mathrm{s}$, the load carrying capacity of the taper flat, polynomial, catenoidal, exponential and truncated cycloidal film profiles are $1985800 \mathrm{~N} / \mathrm{m}, 2129100 \mathrm{~N} / \mathrm{m}, 2123200 \mathrm{~N} / \mathrm{m}$, $2021100 \mathrm{~N} / \mathrm{m}, 1901600 \mathrm{~N} / \mathrm{m}$ respectively. The difference in load carrying capacity between the polynomial and taper flat faced profiles is $143300 \mathrm{~N} / \mathrm{m}$. This increase in load carrying capacity is attributed to the film shape. The polynomial film shape has significant increase in the load carrying capacity when compared to the taper flat faced profile and other film profiles.

When the lubricant viscosity is 0.05 Pas and sliding velocity is $5 \mathrm{~m} / \mathrm{s}$ as shown in Fig. 13, the load carrying capacity of the taper flat, polynomial, catenoidal, exponential and truncated cycloidal film profiles are 160300 $\mathrm{N} / \mathrm{m}, 180970 \mathrm{~N} / \mathrm{m}, 178620 \mathrm{~N} / \mathrm{m}, 166180 \mathrm{~N} / \mathrm{m}, 104950 \mathrm{~N} / \mathrm{m}$ respectively. The difference in load carrying capacity between the polynomial and taper flat faced profiles is 20670 $\mathrm{N} / \mathrm{m}$. This increase in load carrying capacity is attributed to the film shape. The polynomial film shape has significant increase in the load carrying capacity when compared to the taper flat faced profile and other film profiles.

When the lubricant viscosity is 0.05 Pas and sliding velocity is $15 \mathrm{~m} / \mathrm{s}$, the load carrying capacity of the taper flat, polynomial, catenoidal, exponential and truncated cycloidal film profiles are $455800 \mathrm{~N} / \mathrm{m}, 471790 \mathrm{~N} / \mathrm{m}, 465120 \mathrm{~N} / \mathrm{m}$, $459360 \mathrm{~N} / \mathrm{m}, 384870 \mathrm{~N} / \mathrm{m}$ respectively. The difference in load carrying capacity between the polynomial and taper flat faced profiles is $15990 \mathrm{~N} / \mathrm{m}$. This increase in load carrying capacity is attributed to the film shape. The polynomial film shape has significant increase in the load carrying capacity when compared to the taper flat faced profile and other film profiles.

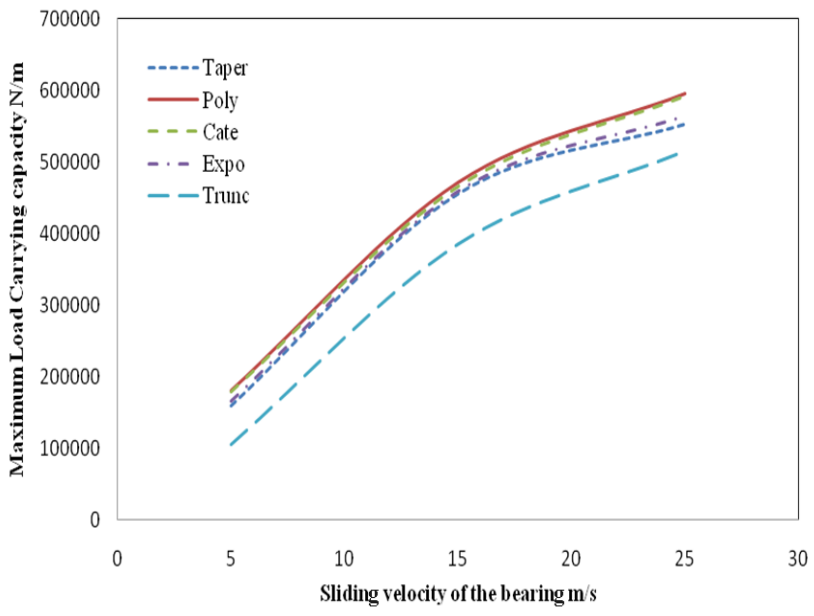

Figure 13. Comparison of Load carrying capacity for all film shapes when viscosity $=0.05$ Pas

When the lubricant viscosity is 0.05 Pas and sliding velocity is $25 \mathrm{~m} / \mathrm{s}$, the load carrying capacity of the taper flat, polynomial, catenoidal, exponential and truncated cycloidal film profiles are $553000 \mathrm{~N} / \mathrm{m}, 595820 \mathrm{~N} / \mathrm{m}, 591600 \mathrm{~N} / \mathrm{m}$, $564660 \mathrm{~N} / \mathrm{m}, 514770 \mathrm{~N} / \mathrm{m}$ respectively. The difference in load carrying capacity between the polynomial and taper flat faced profiles is $42820 \mathrm{~N} / \mathrm{m}$. This increase in load carrying capacity is attributed to the film shape. The polynomial film shape has significant increase in the load carrying capacity when compared to the taper flat faced profile and other film profiles as seen in Fig. 13.

Among the five film profiles, the polynomial film profiles have higher load carrying capacity than other. It is inferred from the above result that the film shape do improve the load carrying capacity with same operating conditions.

\section{Conclusions}

The adiabatically lubricated one dimensional thrust bearing is analyzed with various film profiles such as taper flat face, polynomial, catenoidal, exponential and truncated cycloidal for their effectiveness in improving the load carrying capacity.

- The film profiles do influence the load carrying capacity of the thrust bearings.

- Bearing performance can considerably be improved by changing the shape of the fluid film.

- Load carrying capacity is considerably high for film geometries other than tapered flat face profile.

- Among the film profiles such as taper flat face, polynomial, catenoidal, exponential and truncated cycloidal, the load carrying capacity given by the polynomial film profile is the highest.

\section{Acknowledgements}

We are very grateful to experts for their appropriate and 
constructive suggestions to improve the readability of this paper.

\section{Nomenclature}

$C_{p} \quad$ Specific heat capacity of lubricant $(\mathrm{J} / \mathrm{kgK})$

$F$ Frictional force (Nm)

$h_{\min }$ Minimum film thickness ( $\mathrm{mm}$ )

$h_{\max }$ Maximum film thickness ( $\mathrm{mm}$ )

$i \quad$ Number of iterations

$k \quad$ Thermal conductivity of lubricant $(\mathrm{W} / \mathrm{mK})$

$L \quad$ Pad width of the slider (m)

$N$ constant representing parabolic surface profile $(\mathrm{N}=2)$

$n \quad$ Number of nodes

$p$ Pressure $(\mathrm{Pa})$

$T$ Temperature of lubricant $(\mathrm{K})$

$u \quad$ Sliding velocity of bearing $(\mathrm{m} / \mathrm{s})$

$W \quad$ Load carrying capacity $(\mathrm{N} / \mathrm{m})$

$w$ Lubricant velocity normal to horizontal plane of oil film $(\mathrm{m} / \mathrm{s})$

$\mathrm{X}$ Dimensionless unit $(\mathrm{x} / \mathrm{L})$

$x \quad$ Coordinate in the direction of sliding $(\mathrm{m})$

$z \quad$ Coordinate normal to horizontal plane of oil film (m)

$\alpha \quad h_{\max } / h_{\min }$ (film thickness ratio)

$\gamma$ Exponential coefficient of viscosity $\left(\mathrm{K}^{-1}\right)$

$\eta \quad$ Dynamic viscosity of lubricant (Pas)

$\rho \quad$ Density of lubricant $\left(\mathrm{kg} / \mathrm{m}^{3}\right)$

\section{REFERENCES}

[1] Zakharov, S.M., "Hydrodynamic lubrication research: current situation and future prospects", Journal of Friction and Wear, 31(1), 56-67, 2010

[2] Robinson, C.L., Cameron, A., "Studies in hydrodynamic thrust Bearings I. theory considering thermal and elastic distortions", Philos Trans of the R Soc Ser A 278, 351-366, 1975.
[3] Robinson, C.L., Cameron, A., "Studies in hydrodynamic thrust bearings II.comparison of calculated and measured performance of tilting pads by means of interferometry", Philos Trans of the R Soc Ser A, 278, 367-384, 1975.

[4] Huebner, K.H., "Application of finite element methods to thermo hydro dynamic lubrication", International Journal for Numerical Methods in Engineering, 8:139-165, 1974.

[5] Pinkus, O., Bupara, S.S., "Adiabatic solutions for finite journal bearings", Journal of Lubrication Technology, 101, 492-495, 1979.

[6] Jang, J.Y., Chang, C.C., “Adiabatic analysis of finite width journal bearings with non-Newtonian lubricants", Wear, 122, 63-75, 1988.

[7] El-Gamal, H., "Adiabatic solution to the oscillating slider bearing problem", Wear, 157,389-400, 1992.

[8] Jang, J.Y., Cheng, M.J., Lin, J.F., "Adiabatic solutions of finite-width journal bearings with rough surfaces", Tribology International, 24(6), 373-380, 1991.

[9] Singh, A.P. "Optimum design of tilting pad sliders with one dimensional continuous surface profiles" Wear, 81, 285-309. 1982.

[10] Bagci, C., Singh, A.P., "Hydrodynamic lubrication of finite slider bearings: effect of one-dimensional film shape and their computer aided optimum designs", J Lubrication Technology, 105, 48-66, 1983.

[11] Sharma, R.K., Pandey, R.K., "Thermohydrodynamic analysis of infinitely wide cycloidal profiled pad thrust bearing with rough surface and a comparison to a plane profiled pad", Lubrication Science, 20, 183-203, 2008.

[12] Sharma, R.K., Pandey, R.K., "Experimental studies of pressure distributions in finite slider bearing with single continuous surface profiles on the pads", Tribology International, 42, 1040-1045, 2009.

[13] Andharia, P.I., Gupta, J.L., Deheri, G.M., "Effect of surface roughness on hydrodynamic lubrication of slider bearings", Tribology Transactions, 44(2), 291-297, 2001.

[14] Shah, R.C., Bhat, M.V., "Porous secant shaped slider bearing with slip velocity lubricated by ferrofluid", Industrial Lubrication and Tribology 55(3), 113-115, 2003. 